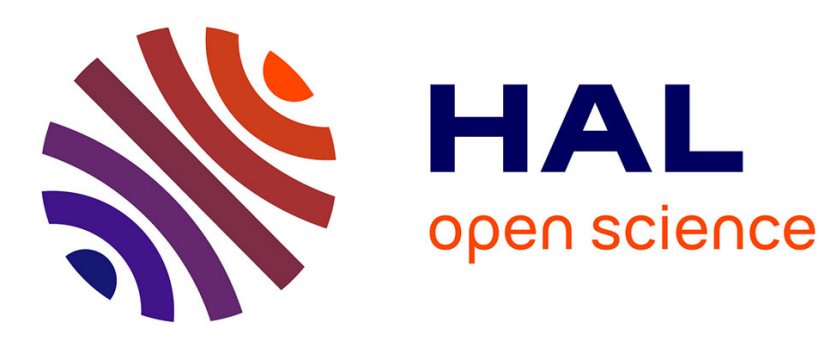

\title{
Non Thermal Plasma Functionalized 2D Carbon-Carbon Composites as Supports for Co Nanoparticles
}

Julien Souquet-Grumey, Philippe Ayrault, Olivier Heintz, Joel Barrault, Jean-Michel Tatibouet, Herve Plaisantin, Jacques Thebault, Sabine Valange, Elodie Fourre

\section{To cite this version:}

Julien Souquet-Grumey, Philippe Ayrault, Olivier Heintz, Joel Barrault, Jean-Michel Tatibouet, et al.. Non Thermal Plasma Functionalized 2D Carbon-Carbon Composites as Supports for Co Nanoparticles. Plasma Chemistry and Plasma Processing, 2014, 34 (2), pp.287-300. 10.1007/s11090-013-9514-0 . hal-01196300

\section{HAL Id: hal-01196300 https://hal.science/hal-01196300}

Submitted on 30 Nov 2020

HAL is a multi-disciplinary open access archive for the deposit and dissemination of scientific research documents, whether they are published or not. The documents may come from teaching and research institutions in France or abroad, or from public or private research centers.
L'archive ouverte pluridisciplinaire HAL, est destinée au dépôt et à la diffusion de documents scientifiques de niveau recherche, publiés ou non, émanant des établissements d'enseignement et de recherche français ou étrangers, des laboratoires publics ou privés. 


\title{
NON THERMAL PLASMA FUNCTIONALIZED 2D CARBON-CARBON COMPOSITES AS SUPPORTS FOR Co NANOPARTICLES
}

Julien SOUQUET-GRUMEY ${ }^{1}$, Philippe AYRAULT ${ }^{1}$, Olivier HEINTZ ${ }^{2}$, Joël BARRAULT ${ }^{1}$, Jean-Michel TATIBOUËT ${ }^{1}$, Hervé PLAISANTIN ${ }^{3}$, Jacques THEBAULT $^{3}$, Sabine VALANGE $^{1, *}$, Elodie FOURRE ${ }^{1, *}$

${ }^{1}$ Institut de Chimie des Milieux et Matériaux de Poitiers (IC2MP), CNRS UMR 7285, Université de Poitiers, Ecole Nationale Supérieure d'Ingénieurs de Poitiers (ENSIP), 1 rue Marcel Doré, 86022 Poitiers Cedex (France)

${ }^{2}$ Laboratoire Interdisciplinaire Carnot de Bourgogne, CNRS UMR 6303, Université de Bourgogne, 9, avenue Alain Savary, BP 47870, 21078 Dijon cedex (France)

${ }^{3}$ Snecma Propulsion Solide, Les 5 chemins, 33185 Le Haillan (France)

\begin{abstract}
Novel two-dimensional carbon-carbon composites made of carbon nanofibers (CNFs) supported on a carbon preform were functionalized by non thermal plasma treatment (room temperature, atmospheric pressure, humid air), before being used as supports for metallic cobalt nanoparticles. It was shown that the degree of functionalization of the carbon nanofibers depends on the plasma power input, the treatment time and the CNF loading. The size of the cobalt nanoparticles generated after subsequent reduction of the Co-containing plasma treated $\mathrm{CNF} / \mathrm{C}$ composites under hydrogen flow seems to be independent of the amount of supported cobalt. Changes in surface characteristics were analyzed using thermogravimetric analyses coupled to a mass spectrometer (TGA-MS), X-Ray photoelectron spectroscopy (XPS) analyses and Raman spectroscopy. Transmission electron microscopy (TEM) was used to complementary characterize the final size, dispersion and location of the so generated Co nanoparticles.
\end{abstract}


Keywords: carbon nanofibers, carbon composites, non thermal plasma, cobalt nanoparticles, XPS

*Corresponding authors. Tel: 0033549453682. E-mails: elodie.fourre@ univ-poitiers.fr (E. Fourré) ; sabine.valange@univ-poitiers.fr (S. Valange)

\section{Introduction}

Carbon nanotubes (CNTs) and carbon nanofibers (CNFs) are of great interest due to their exceptional mechanical, thermal and electronic properties in many applications including nanocomposites, gas storage materials, electronics, chemical sensors and heterogeneous catalysis. However, chemical applications are challenged by the inertness of the carbon materials due to the lack of functional sites after purification. Various covalent and noncovalent surface derivatization routes have been developed to insert functional groups on the surface of CNTs and CNFs. One of the approaches consists in a strong oxidizing treatment with $\mathrm{KMnO}_{4}$ or $\mathrm{H}_{2} \mathrm{O}_{2}$ or mineral acids such as $\mathrm{HNO}_{3}, \mathrm{H}_{2} \mathrm{SO}_{4}$, or $\mathrm{HCl}$ [1-7], but with damaging effects of the outer electronic surface of the carbon materials. An alternative way to the surface oxidation treatment, in milder conditions, is the functionalization of CNFs by non thermal plasma. Different types of plasma were tested for the functionalization of the CNT or CNF materials. It included microwave, dielectric barrier discharge (DBD), radiofrequency and corona discharge plasmas using various type of gases such as $\mathrm{O}_{2}, \mathrm{Ar} / \mathrm{O}_{2}, \mathrm{NH}_{3}$, air, air/ $\mathrm{H}_{2} \mathrm{O}$, and $\mathrm{N}_{2}$ [8-17]. The plasma discharge generates highly energetic electrons and activated species such as radicals and ions which can interact with the surface of the CNTs and CNFs, in particular with the aromatic $\mathrm{C}-\mathrm{C}$ bonds. These interactions are able to create active sites leading to the grafting of functional groups that can be further used for the growth of metallic or oxidic nanoparticles for catalytic applications, as well as for the reinforcement of adhesive properties between the CNF and a polymeric matrix [18-19]. Compared with the chemical 
treatments, the non thermal plasma method presents many advantages since it is a fast, non destructive method with low energy consumption and it can be generated in air, at atmospheric pressure, thus avoiding the use of an expensive vacuum system or special gases.

A large number of studies have been published concerning the growth of nanoparticles on carbon nanotubes or nanofibers following different chemical treatments [20-24]. Very few, however, describe a non thermal plasma functionalization of CNFs prior to their use as supports for metallic nanoparticles [25-26].

In the present work, the plasma functionalization of novel 2D carbon-carbon composites constituted of carbon nanofibers supported on a carbon preform is presented. The pristine and air plasma-treated $\mathrm{CNF} / \mathrm{C}$ composites were further decorated with Co nanoparticles. The chemical functional groups (i.e. oxygen-based species) generated by the non-thermal plasma treatment on the surface of the composites should favor strong interactions with a cobalt precursor, thereby leading after reduction to a homogeneous distribution of supported Co nanoparticles. Such surface functional groups are indeed expected to act as anchoring sites for the cobalt nanoparticles, thus allowing their size, dispersion and stability to be controlled. The effect of treatment time and plasma power input on the functionalization degree (type and amount of oxygen surface functionalities) of the $\mathrm{CNF} / \mathrm{C}$ composites and hence on the cobalt particles formation was characterized through TGA-MS, XPS and TEM analyses.

\section{Experimental}

\subsection{DBD plasma reactor}

The scheme of the plasma reactor is shown in figure 1. The plasma reactor is of DBD type and is formed by a box $(100 \times 100 \times 12 \mathrm{~mm})$ made of glass plates ( $4 \mathrm{~mm}$ thick). 


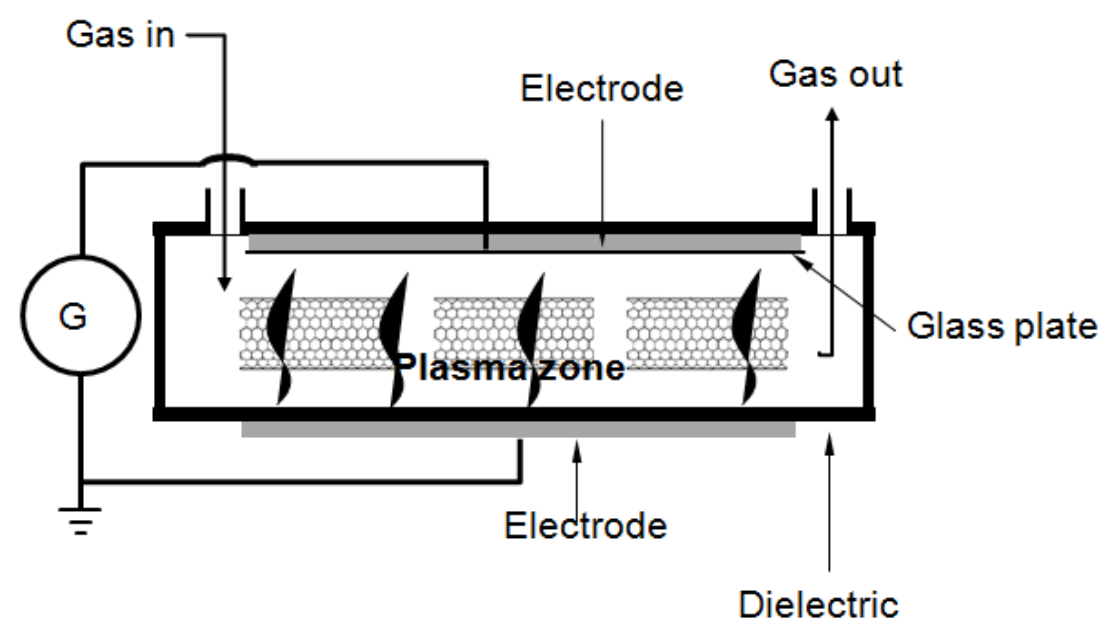

Figure 1 Schematic representation of the DBD plasma reactor

One electrode is a copper film $(50 \times 50 \mathrm{~mm})$ fixed outside on the bottom of the box. The other electrode $(50 \times 50 \mathrm{~mm})$ is made of a copper grid placed inside the box and covered by a thin glass plate $(1 \mathrm{~mm}$ thick) in order to avoid the direct contact of the mesh with the carbon fibers. The dielectric barriers are then formed by the glass wall of the box and the thin glass plate. The gap between the glass wall and the thin glass plate is $2 \mathrm{~mm}$. The $\mathrm{CNF} / \mathrm{C}$ composites were placed inside the reactor in the zone of the plasma discharge. This position enhances interactions between the plasma discharge and the C-C bonds on the outer surface of the nanofibers, thereby leading to various oxygen superficial functionalities.

The electrodes are connected to a bi-polar pulse generator (A2E Technologies-Enertronic). The applied maximum voltage and the frequency of the bi-polar pulse can be varied between 0-40 kV and 1-4000 $\mathrm{Hz}$ respectively. The electrical parameters are measured via two high voltage probes (Lecroy, PPE20KV-CC) and one current probe (Stangenes Industry $60 \mathrm{MHz}$ ) connected to a digital oscilloscope (Lecroy WaveSurfer 64Xs-A, $600 \mathrm{MHz}$ ).

The experiments were carried out under a humid air flow $\left(0.5-1.5 \mathrm{~mL} / \mathrm{min}, 1.5 \% \mathrm{~mol}_{2} \mathrm{O}\right)$ at room temperature. The plasma treatment duration was comprised between 30 to $180 \mathrm{~min}$. All the treatments were performed at a constant frequency of $2000 \mathrm{~Hz}$. 


\subsection{Carbon nanocomposites}

The carbon-carbon composites were manufactured by SNECMA PROPULSION SOLIDE Company (SAFRAN group). Such composites consist of a macroscopic 2D carbon preform (carbon fibers) coated with different percentages of carbon nanofibers.

\subsection{Characterization}

The morphology of the pristine and Co-containing air-plasma treated CNF/C composites was determined by transmission electron microscopy (TEM) using a JEOL 2100 UHR (voltage $200 \mathrm{kV}, \mathrm{LaB}_{6}$ filament). Before characterization, the samples were treated in an ethanol ultrasonic bath and dried in air. The image acquisition was carried out using a Gatan $2 \mathrm{~K} 2 \mathrm{~K}$ Ultrascan camera. 2D Fourier transforms were performed in order to determine the structure and the d-spacing of the metallic particles. The obtained data were compared to powder diffraction data 2002 and structural information obtained from ICSD Inorganic Crystal Structure Database 2001.

The samples were characterized by thermogravimetric analyses coupled with a mass spectrometer (TGA-MS) under a nitrogen or argon flow $\left(100 \mathrm{~mL} / \mathrm{min}, 5^{\circ} \mathrm{C} / \mathrm{min}\right)$. X-ray electron spectroscopy (XPS) was carried out on a PHI 5000 Versaprobe. The X-ray source was the monochromatic $\mathrm{Al} \mathrm{K}_{\alpha}$ radiation (energy of $1486.7 \mathrm{eV}$ ). The CASA XPS program with a Gaussian-Lorentzian mix function and Shirley background subtraction was employed. FWHM values were fixed at a maximum limit of $2 \mathrm{eV}$ for all the peaks. Binding energies were calibrated using the main $\mathrm{C} 1 \mathrm{~s}$ peak at $284.5 \mathrm{eV}$ as internal standard.

The Raman spectra were acquired with a HORIBA JOBIN YVON Labram HR800UV spectrometer equipped with a CCD (charge coupled device) detector cooled down by Peltier effect and using an $\mathrm{Ar}^{+}$laser at $514.5 \mathrm{~nm}$ wavelength as excitation source. 
ICP analyses for cobalt content were performed on a Perkin-Elmer 5300DV apparatus by IANESCO-Chimie/Poitiers.

2.4 Synthesis of cobalt nanoparticles on the CNF/C composite supports.

The Co-containing CNF/C composites were prepared by using a two steps procedure, namely by ionic exchange or by incipient wetness impregnation of a cobalt precursor on the surface of the pristine and plasma-treated composites.

\subsubsection{Samples prepared by ionic-exchange}

The CNF/C composites $(100 \mathrm{mg})$ were placed in suspension in an ethanol solution $(15 \mathrm{~mL})$ containing $2.6 \mathrm{wt} \%$ of cobalt (relative to the carbon support). Cobalt nitrate $\mathrm{Co}\left(\mathrm{NO}_{3}\right)_{2}, 6 \mathrm{H}_{2} \mathrm{O}$ was chosen as metallic precursor. After stirring for $1 \mathrm{~h}$, the suspension was filtered and dried at $120{ }^{\circ} \mathrm{C}$ for $15 \mathrm{~h}$. The samples were finally reduced for $10 \mathrm{~h}$ under $\mathrm{H}_{2}$ flow from room temperature to $450{ }^{\circ} \mathrm{C}\left(3{ }^{\circ} \mathrm{C} / \mathrm{min}\right.$ ramp $)$.

\subsubsection{Samples prepared by incipient wetness impregnation}

The pristine and air plasma-treated CNF-C composites were impregnated by the cobalt nitrate precursor dissolved in a minimal volume of ethanol, thus avoiding the filtration step. Ethanol was then evaporated very slowly in an oven heated at $40{ }^{\circ} \mathrm{C}, 60{ }^{\circ} \mathrm{C}$ and then at $120{ }^{\circ} \mathrm{C}$ in order to favor a homogeneous dispersion of the Co precursor on the surface of the $\mathrm{CNF} / \mathrm{C}$ composites. These samples were further reduced by $\mathrm{H}_{2}$ at $420{ }^{\circ} \mathrm{C}$ to minimize the deterioration of the carbon nanofibers by direct hydrogenation into $\mathrm{CH}_{4}$.

\section{Results}

\subsection{Plasma activation}

\subsubsection{TGA-MS under Ar flow}


Four CNF/C composites with different CNF content (Table 1) were analyzed by TGA under argon flow after various plasma treatments under humid air. The total weight loss was calculated over the temperature range of $100-900{ }^{\circ} \mathrm{C}$. The weight loss of the untreated $\mathrm{CNF} / \mathrm{C}$ composite remains very low (less than $0.5 \mathrm{wt} \%$ ) and could be due to residual water, impurities and/or unstable nanofibers.

\begin{tabular}{|c|c|c|c|c|}
\hline \multirow{2}{*}{ Sample } & \multirow{2}{*}{$\begin{array}{c}\text { CNF } \\
\text { content } \\
\text { (wt\%) }\end{array}$} & \multicolumn{2}{|c|}{$\begin{array}{c}\text { Plasma treatment } \\
\text { conditions }\end{array}$} & \multirow{2}{*}{$\begin{array}{c}\text { Total weight } \\
\text { loss }(\%) \\
\left(100^{\circ} \mathrm{C}-900^{\circ} \mathrm{C}\right)\end{array}$} \\
\hline & & $\begin{array}{c}\text { Power } \\
(\mathrm{W})\end{array}$ & $\begin{array}{l}\text { Time } \\
(\min )\end{array}$ & \\
\hline$B$ & 44 & - & - & $<0.5$ \\
\hline$D$ & 28 & - & - & $<0.5$ \\
\hline$A$ & 0 & 34.5 & 70 & $<0.5$ \\
\hline$B$ & 44 & 34.5 & 30 & 4.0 \\
\hline B & 44 & 34.5 & 70 & 5.9 \\
\hline$B^{*}$ & 44 & 34.5 & 70 & 6.4 \\
\hline B & 44 & 34.5 & 180 & 6.1 \\
\hline B & 44 & 11.5 & 70 & 4.4 \\
\hline$B$ & 44 & 11.5 & 180 & 6.8 \\
\hline$D$ & 28 & 35.8 & 70 & 3.4 \\
\hline $\mathrm{C}$ & 37 & 34.5 & 70 & 5.2 \\
\hline
\end{tabular}

$*$ Humid air flow rate $=1.5 \mathrm{~L} / \mathrm{min}$

Table 1 Weight loss percentages estimated from TGA experiments for different samples as a function of the plasma treatment parameters (humid air flow rate $=0.5 \mathrm{~L} / \mathrm{min}$ )

These data indicate that the observed weight loss for the air plasma-treated CNF/C composites is due to the removal of surface species arising from the plasma treatment, so that the weight loss can be directly related to the functionalization degree of the carbon surface. The modification of the flow rate has no significant effect on the amount of functional groups generated on the surface of the carbon composites. 
Interestingly, the weight loss, after a treatment time of $180 \mathrm{~min}$ at $11.5 \mathrm{~W}$, is nearly the same than the one obtained after $70 \mathrm{~min}$ at $34.5 \mathrm{~W}$. This strongly suggests that, in first approximation, the degree of functionalization depends on the total energy, $E$, deposited by the non-thermal plasma treatment (Figure 2), with however a slightly higher efficiency for longer treatment times with a low power input. Low input energies were chosen to avoid degradation of the samples, thus long treatment times were set to optimize the functionalization of the $\mathrm{CNF} / \mathrm{C}$ composites.

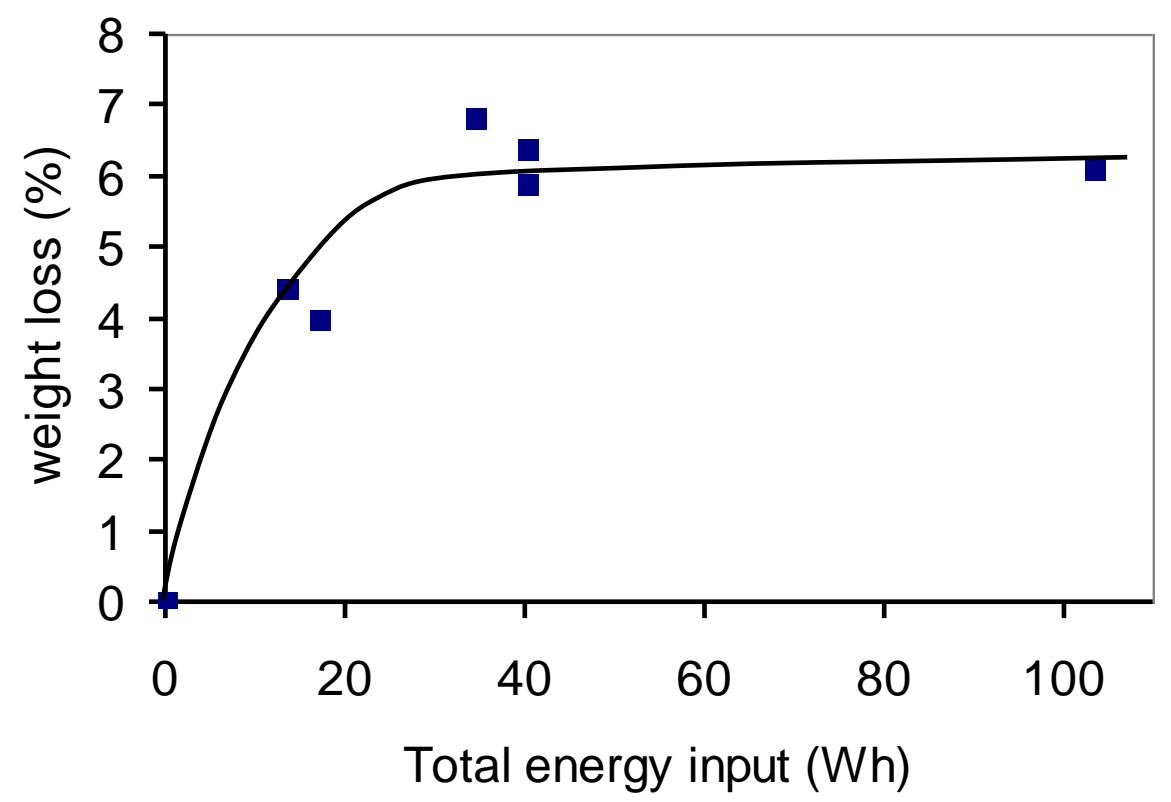

Figure 2 Effect of the plasma total energy input on the weight loss of sample $B$. $\mathrm{E}=$ power $\times$ plasma treatment time

Whatever the time and the power input of the plasma treatment, a plateau seems to be reached for a total energy of $40 \mathrm{Wh}(144 \mathrm{~kJ})$. The amount of generated surface functional groups (Figure 3) increases with the CNF content on the $\mathrm{CNF} / \mathrm{C}$ composites, strongly suggesting that only the CNF are functionalized by the plasma treatment. 


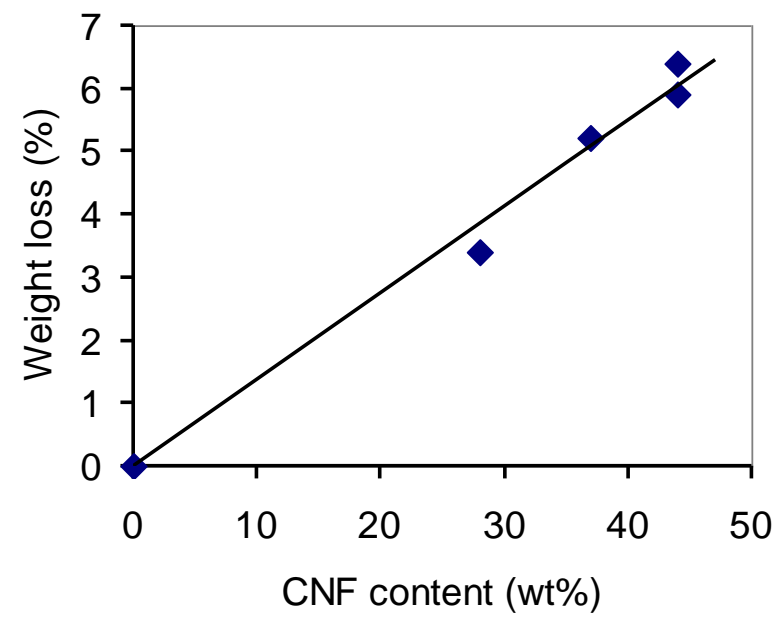

Figure 3 Effect of the CNF content on the CNF/C composite weight loss

This result was confirmed by the very low weight loss after plasma treatment of the carbon material that is not covered by any CNFs, namely the carbon preform (sample A, Table 1).

The TGA coupled with a mass spectrometer gave information on the chemical nature of the functional groups. Figure 4 shows the variations of the mass spectrum ions $\mathrm{m} / \mathrm{e}=44\left(\mathrm{CO}_{2}\right)$, $\mathrm{m} / \mathrm{e}=30(\mathrm{NO}), \mathrm{m} / \mathrm{e}=28\left(\mathrm{CO}\right.$ and $\left.\mathrm{N}_{2}\right)$ and $\mathrm{m} / \mathrm{e}=18\left(\mathrm{H}_{2} \mathrm{O}\right)$ observed during a TGA experiment under argon of the CNF/C composite containing $44 \mathrm{wt} \% \mathrm{CNF}$ (sample B) before and after non-thermal plasma treatment $(34.5 \mathrm{~W}, 180 \mathrm{~min})$. The profile of the variation of ionic currents corresponding to the ions $\mathrm{m} / \mathrm{e}=28$ and $\mathrm{m} / \mathrm{e}=30$ for the air plasma treated $\mathrm{CNF} / \mathrm{C}$ composite indicate that the chemical species associated with the weight loss could contain nitrogen $\left(\mathrm{m} / \mathrm{e}=30: \mathrm{NO}\right.$ and $\left.\mathrm{m} / \mathrm{e}=28: \mathrm{N}_{2}\right)$ and carboxylic units $(\mathrm{m} / \mathrm{e}=28: \mathrm{CO})$. 

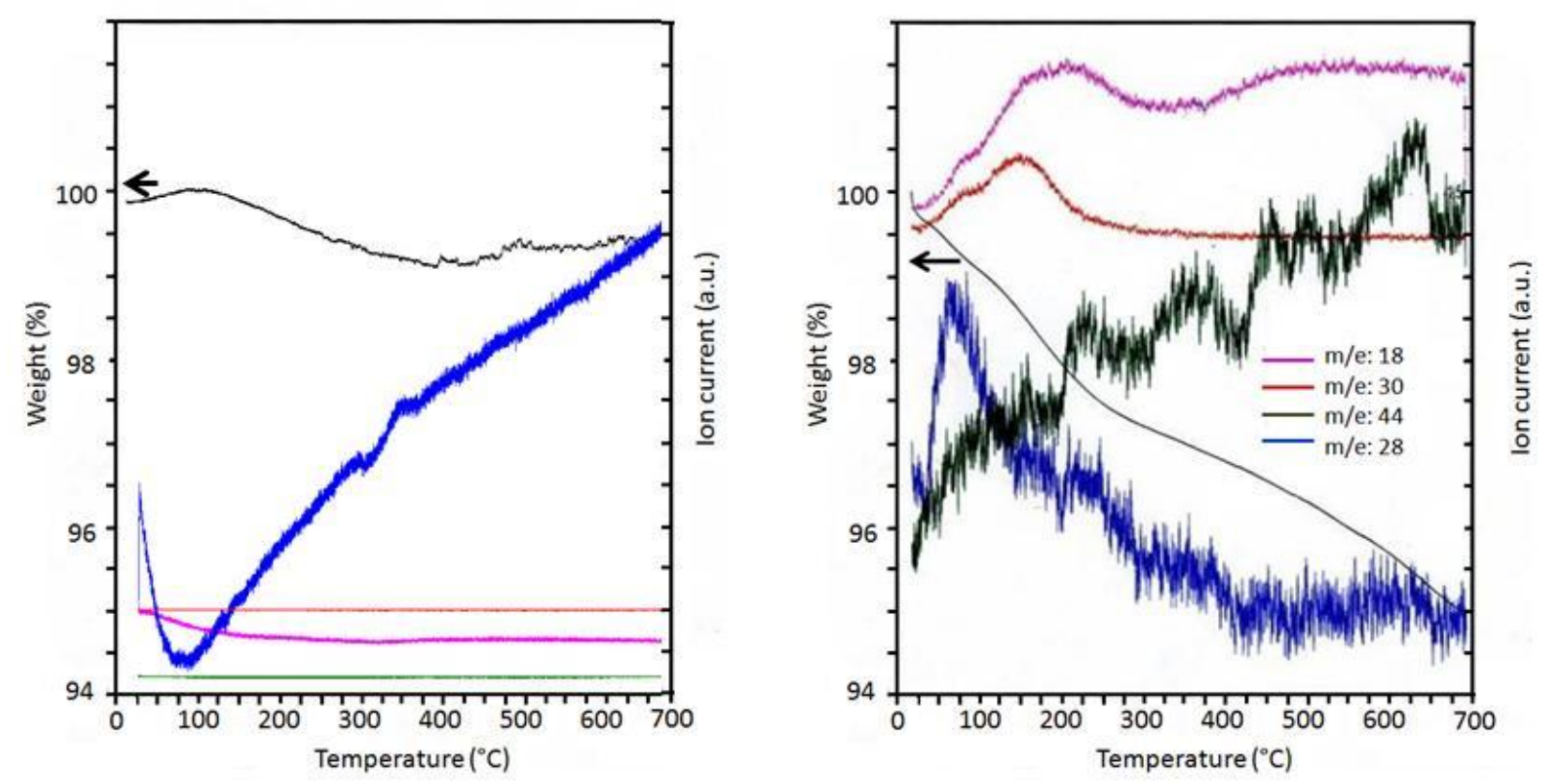

Figure 4 Ionic currents from mass spectrometer and weight loss of pristine (left) and air plasma treated (right) sample B as a function of temperature (under Ar flow)

\subsubsection{XPS characterization}

Characterization of the $\mathrm{CNF} / \mathrm{C}$ composite containing 37wt\% CNF (sample C) after various air plasma treatment times has been performed by XPS. The results concerning the $\mathrm{C}, \mathrm{N}$ and $\mathrm{O}$ surface relative abundance are displayed in figure 5 . 


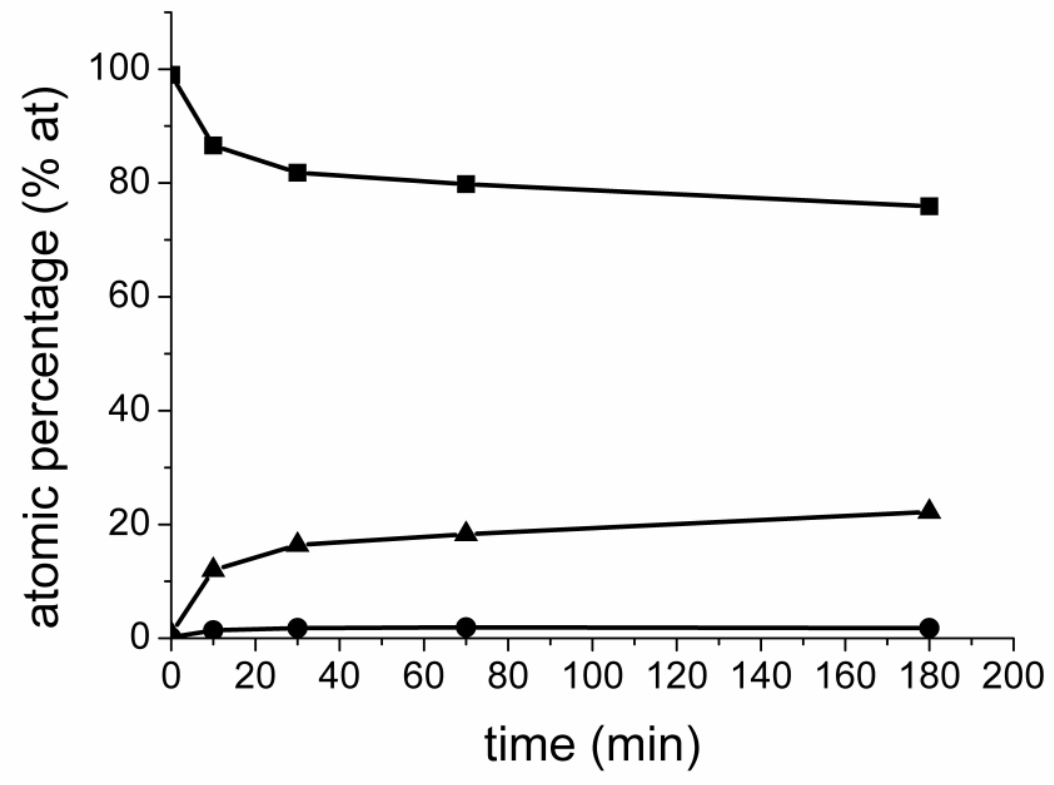

Figure 5 Surface atomic percentages of carbon $(\square)$, nitrogen $(\bullet)$ and oxygen $(\Delta)$ of sample C, measured by XPS, as a function of the plasma treatment time (power=34.5 W)

The oxygen atom percentage changed from $0.8 \%$ for the untreated $\mathrm{CNF} / \mathrm{C}$ composite to $12 \%$ after 10 min activation while the nitrogen atom percentage varied from $0.2 \%$ to $1.4 \%$. The oxygen and nitrogen contents tended to stabilize after $20-30$ min to then reach $22.2 \%$ and 1.8 $\%$ after 3 h, respectively. According to the results obtained by TGA (Table 1), no more modifications of the carbon surface occurred after 30 min of plasma treatment, which corresponds to a total energy input of about $20 \mathrm{Wh}(72 \mathrm{~kJ})$.

On the pristine $\mathrm{CNF} / \mathrm{C}$ composite, there was 4 times more oxygen than nitrogen. This ratio changed to 12 times more oxygen after $3 \mathrm{~h}$ of plasma treatment although the plasma treatment, which is also able to activate nitrogen molecules, is done under air $\left(\mathrm{O}_{2} / \mathrm{N}_{2}=21 / 79\right.$ mol\%). Naseh and al. [11] explained that the lack of nitrogen functionalities is due to the weakness of the $\mathrm{C}-\mathrm{N}$ bond compared to the $\mathrm{C}-\mathrm{O}$ bond.

The deconvolution of the $\mathrm{C} 1 \mathrm{~s}$ peak at $284.4 \mathrm{eV}$ (Figure 6) gave information on the nature of the different carbonaceous functions present at the surface of the CNFs as a function of 
treatment time. The main peak at $284.4 \mathrm{eV}$ refers to sp2-carbon atoms from the nanofibers. A satellite peak of the Csp2 related to the $\pi-\pi^{*}$ transition is situated at $291 \mathrm{eV}$. The other components, located at $285.2 \mathrm{eV}, 286.4 \mathrm{eV}, 287.7 \mathrm{eV}$ and $289.0 \mathrm{eV}$, correspond respectively to Csp3, C-O- (epoxy, ether, hydroxyl), $\mathrm{C}=\mathrm{O}$ (carbonyl and quinone) and $\mathrm{O}-\mathrm{C}=\mathrm{O}$ (carboxylic acid, ester, anhydride) [25, 27-28]. The shape of the C1s peak was modified with the plasma treatment time, characterizing an important alteration of the surface carbon-based species.

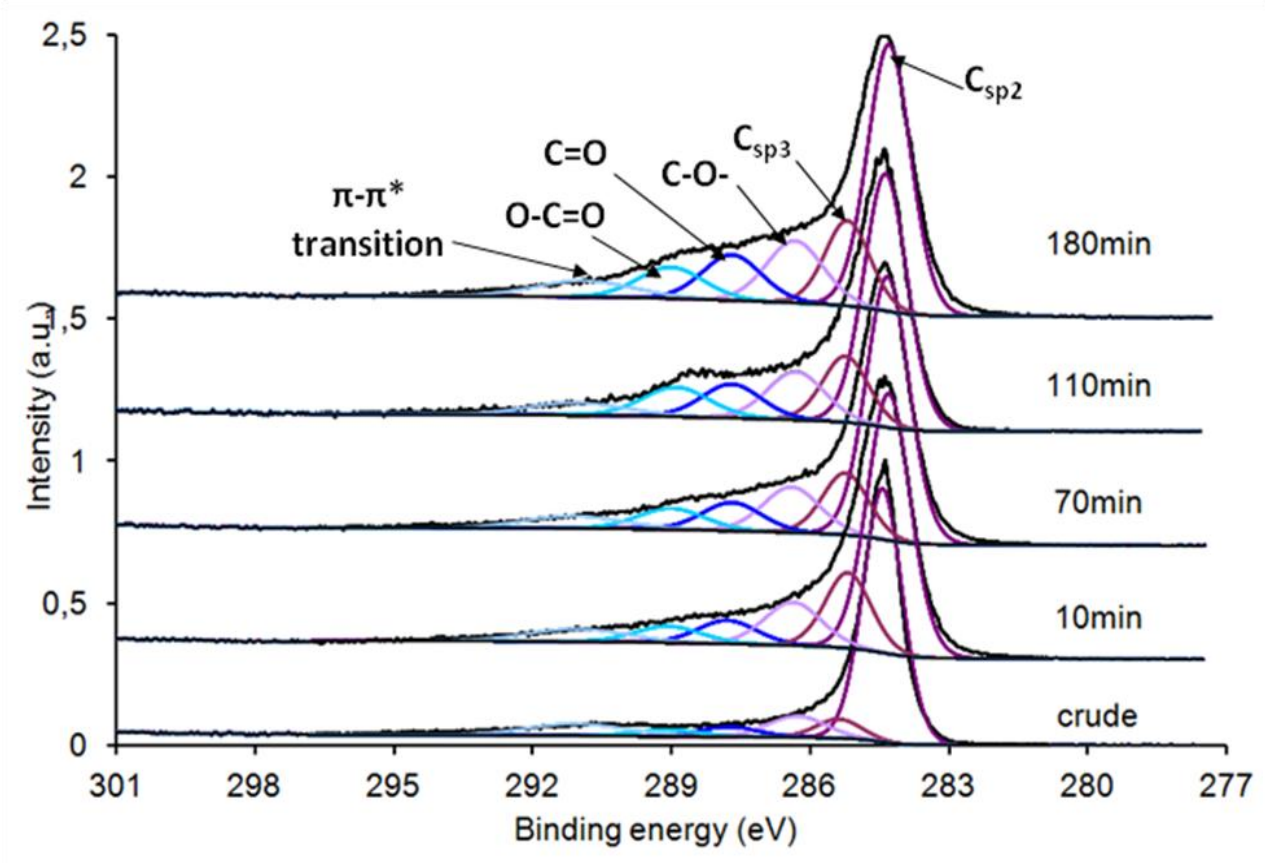

Figure 6 C1s deconvolution peak of sample $C$ after various plasma treatment time

As the time increased, it affected the intensity of the carbon- and oxygen-based species. This evolution is displayed in figure 7. It appeared that the main evolution occurred during the first 10 min of plasma treatment, where the Csp2 peak decreased to the benefit of Csp3 peak. By increasing the treatment time, the Csp2 to Csp3 ratio did not vary significantly but the oxygen surface functionalities increased until they reached a plateau after about 70 min of treatment. 


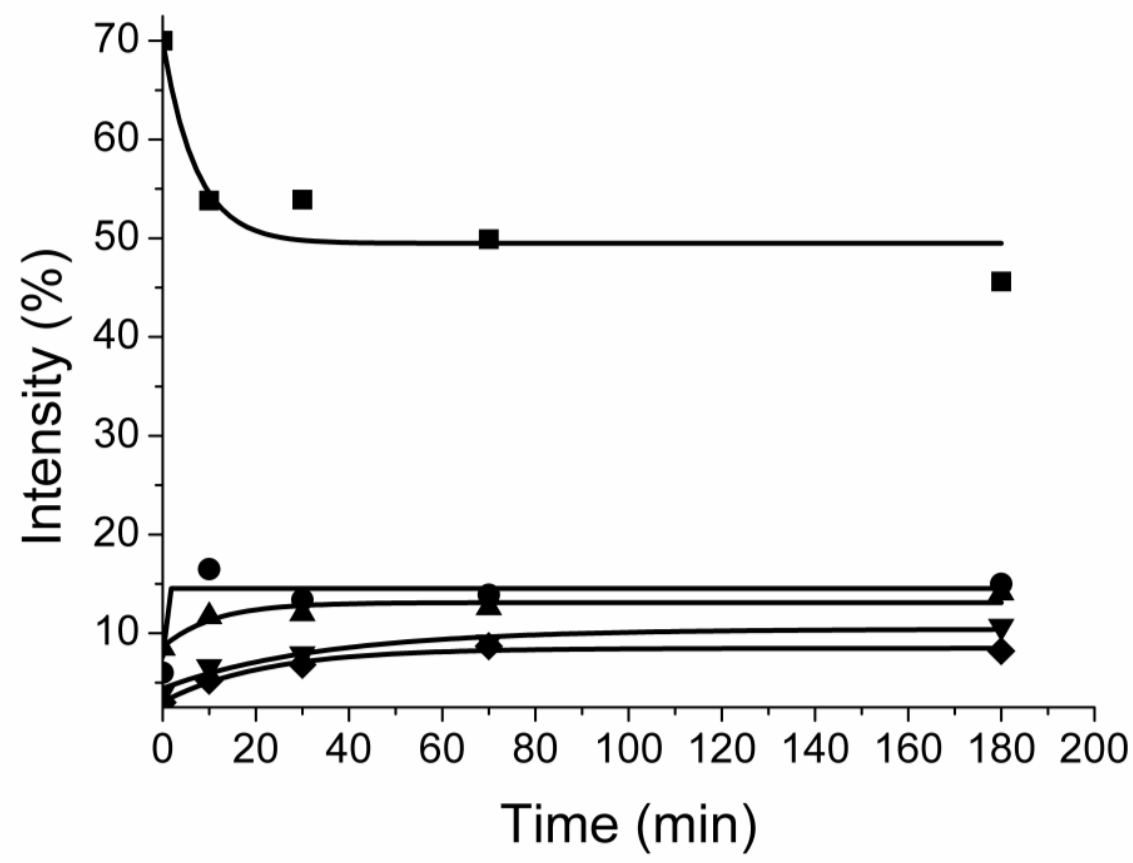

Figure 7 Repartition of the peak intensities of the carbon-based species with respect to Csp2 as a function of plasma treatment time $(P=34.5$ W). Legend: Csp2 $(\square)$, Csp3 $(\bullet)$, $\mathrm{C}-\mathrm{O}(\Delta), \mathrm{C}=\mathrm{O}(\nabla)$ and $\mathrm{O}-\mathrm{C}=\mathrm{O}(\diamond)$

The $\pi$ bonds of the $\mathrm{C}=\mathrm{C}$ functions are the most prone to intervene due to their high reactivity. They were modified by the action of the radicals and excited species generated by the plasma and led to an increase of the Csp3 carbon content. The decrease of the surface modification after 10 min of activation was due to the decrease of available sp2 carbon. First, the accessible $\mathrm{C}=\mathrm{C}$ functions were modified by the plasma treatment leading to the formation of oxygen and nitrogen-based species.

As the plasma treatment time increased, the amount of potential attack sites decreased and the evolution stagnated (surface saturation). The radicals and excited species, continuously generated by the plasma, reacted with the surface functional groups leading to the partial conversion of $\mathrm{C}-\mathrm{O}$ - groups into $\mathrm{C}=\mathrm{O}$ (carbonyl, quinone) and $\mathrm{O}-\mathrm{C}=\mathrm{O}$ (carboxylic acids, ester and anhydride). 


\subsubsection{Raman spectroscopy}

The air plasma treated CNF/C composites were also characterized by Raman spectroscopy. A typical Raman spectrum of CNTs or CNFs presents two main features: a strong band around $1350 \mathrm{~cm}^{-1}$, called D-line assigned to disordered graphitic carbon and a second peak around $1600 \mathrm{~cm}^{-1}$ corresponding to tangential stretching transitions of graphite $C$ atoms [29]. In the following analysis, the evolution of the peaks representatives of the graphitic carbon ( $\mathrm{G}$ band at $1600 \mathrm{~cm}^{-1}$ ) and disordered carbon (D band at $1350 \mathrm{~cm}^{-1}$ ) as a function of the plasma treatment time is shown in figure 8 .

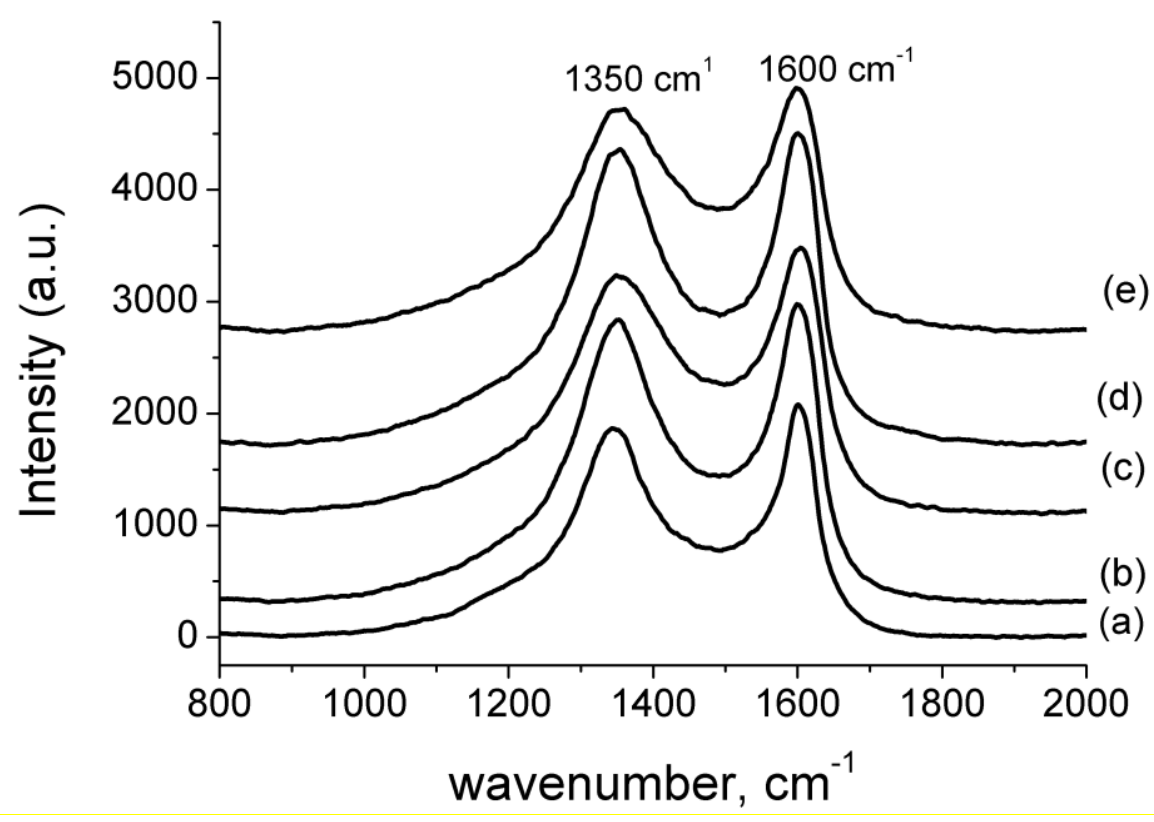

Figure 8 Raman spectra of the pristine CNF/composite (sample C) (a) and after plasma treatment: (b) $10 \mathrm{~min}$, (c) $30 \mathrm{~min}$, (d) $70 \mathrm{~min}$, (e) $180 \mathrm{~min}$

The ratio of the integrated peak areas of the $\mathrm{D}$ band over the $\mathrm{G}$ band gave information on the evolution of the $\mathrm{CNF} / \mathrm{C}$ composite structure after the plasma treatment. The results are presented in Table 2. 


\begin{tabular}{|c|c|}
\hline Plasma treatment time & $\frac{I D}{I G}$ \\
\hline None & 0.85 \\
\hline $10 \mathrm{~min}$ & 0.99 \\
\hline $30 \mathrm{~min}$ & 1.01 \\
\hline $70 \mathrm{~min}$ & 1.02 \\
\hline $180 \mathrm{~min}$ & 1.02 \\
\hline
\end{tabular}

Table 2 Ratio of integrated peak areas of Raman D band over G band

The Raman ID/IG ratio showed an increase within the first 10 min of plasma treatment, indicating an increase of the CNF disordered graphitic species. Surface modifications of CNTs or CNFS based on traditional harsh oxidative methods are well known to generate oxygen-based functional groups on the surface of the carbon materials, but they also strongly alter the electronic structure of their outer surface [6]. Our results demonstrate that a non thermal plasma treatment leads to the functionalization of the $\mathrm{CNF} / \mathrm{C}$ composites under mild conditions, without degradation of the nanofibers.

\subsection{Cobalt-containing CNF/C composites}

Cobalt-supported CNF-C composites were first prepared by an ionic exchange procedure on the composites treated by plasma for $70 \mathrm{~min}$ at $34.5 \mathrm{~W}$, as well as on the pristine carbon preform (sample A) and the CNF/C composite with 37 wt\% CNF (sample C). These plasma treatment parameters were chosen according to the TGA analysis. At this energy input, the weight loss tends to stabilize at $70 \mathrm{~min}$ and longer treatment times did not enhance significantly the amount of oxygen-based surface species. According to the experimental conditions, a maximum of $2.6 \mathrm{wt} \%$ of cobalt species could be deposited on the surface of the samples. The cobalt content of the samples was determined by ICP analyses (Table 3). 


\begin{tabular}{|c|c|c|}
\hline Sample & Procedure & Co content (wt \%) \\
\hline$A$ & Ionic exchange & 0.04 \\
\hline C untreated & Ionic exchange & 0.1 \\
\hline C plasma treated ${ }^{\mathrm{a}}$ & Ionic exchange & 0.7 \\
\hline D plasma treated ${ }^{\mathrm{a}}$ & Ionic exchange & 0.5 \\
\hline C plasma treated ${ }^{\mathrm{a}}$ & Incipient wetness & 2.1 \\
\hline
\end{tabular}

${ }^{a}$ Plasma treatment: $70 \mathrm{~min}, 34.5 \mathrm{~W}$

\section{Table 3 Cobalt content from ICP analyses}

The air plasma treated sample A $(0 \% \mathrm{CNF})$ contained a very low cobalt amount suggesting a weak interaction between the metallic precursor and the surface on the carbon prefrom uncovered with carbon nanofibers despite the plasma activation. The results obtained on the untreated sample $\mathrm{C}$ showed the importance of plasma activation prior to the decoration of the carbon support with an active phase. The plasma treated C sample, containing $27 \%$ of CNF, showed the highest Co content $(0.7 \mathrm{wt} \%)$ from the whole Co-based CNF/C composite series prepared by ionic exchange. Such data indicated that strong interactions exist between the carbon support and the metallic precursor, despite a protocol including a filtration step. This result is promising since the ionic exchange route is usually inappropriate to favor a high dispersion of an active phase on untreated carbon carrier especially for non noble metals. Different Co contents were determined on the plasma treated CNF/C composites D and C, which can be explained by the difference on the nanofibers content of the two samples $(28 \%$ and $37 \%$, respectively). The percentage of ionic exchanged cobalt is then dependant of the percentage of CNFs at the surface of the composites and is consistent with the functionalization of the sole CNFs by the air plasma treatment as previously suggested.

Following the ionic exchange route, the metallic precursor was directly reduced into metallic Co under $\mathrm{H}_{2}$. 
Bezemer et al. [30] applied this protocol for the formation of metallic Co particles on carbon nanofibers. Therefore, a reduction of $450{ }^{\circ} \mathrm{C}$ under $\mathrm{H}_{2}$ was chosen for the Co-containing $\mathrm{CNF} / \mathrm{C}$ composite prior to TEM characterization. Cobalt nanoparticles supported on $\mathrm{CNF}$ are clearly visible (figure 9) after reduction under $\mathrm{H}_{2}$. The size of the Co nanoparticles is comprised between $2 \mathrm{~nm}$ and $5 \mathrm{~nm}$ and they are homogeneously distributed on the fibers. According to the TEM analysis and 2D Fourier transform diffractograms, they are constituted of particles of sizes 1-2 nm of metallic Co with cubic symmetry. The inset in figure $9 \mathrm{~d}$ shows the 2D Fourier transform of the highlighted particle, indicating the presence of an additional CoO phase $\left(d_{111}=0.24 \mathrm{~nm} ; d_{200}=0.21 \mathrm{~nm}\right)$ on the surface of the metallic Co nanoparticles. The CoO layer arises from a partial surface reoxidation by contact with air or during preparation for TEM imaging, as already observed by the group of de Jong for metallic cobalt supported on carbon nanofibers [30]. These results show a high and homogeneous dispersion of the cobalt nanoparticles indicating that the plasma treatment favors the formation of a significant amount of surface functional groups able to interact with a metallic precursor and leading after reduction to a homogeneous distribution of well-dispersed Co particles. 

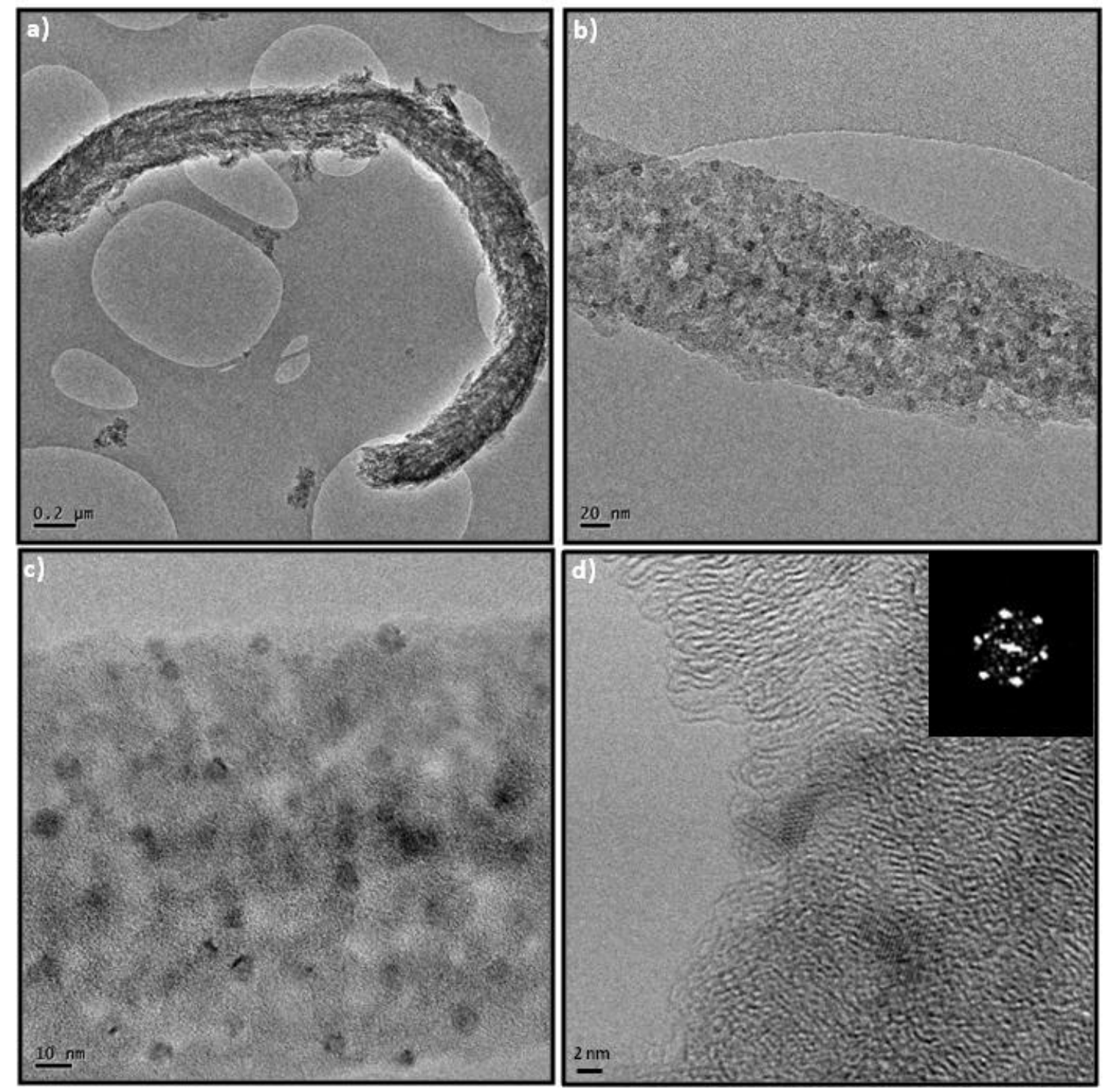

Figure 9 TEM images of the Co-containing CNF/C material (sample C) prepared by the ionic exchange route on the air plasma treated composite (power $=34.5 \mathrm{~W}, 70 \mathrm{~min}$ ) and further reduced under $\mathrm{H}_{2}$ at $450^{\circ} \mathrm{C}(0.7 \mathrm{wt} \% \mathrm{Co})$

In order to increase the cobalt content on the CNF-C composites, we have also used the incipient wetness impregnation procedure (minimum of solvent) with the plasma treated sample C. The cobalt metal loading measured by ICP was $2.1 \mathrm{wt} \%$. The impregnated Co content according to the incipient wetness procedure was three times higher than that obtained by ionic exchange (Table 2). The catalyst was then reduced at $420{ }^{\circ} \mathrm{C}$ under $\mathrm{H}_{2}$ and characterized by TEM (Figure 10). 

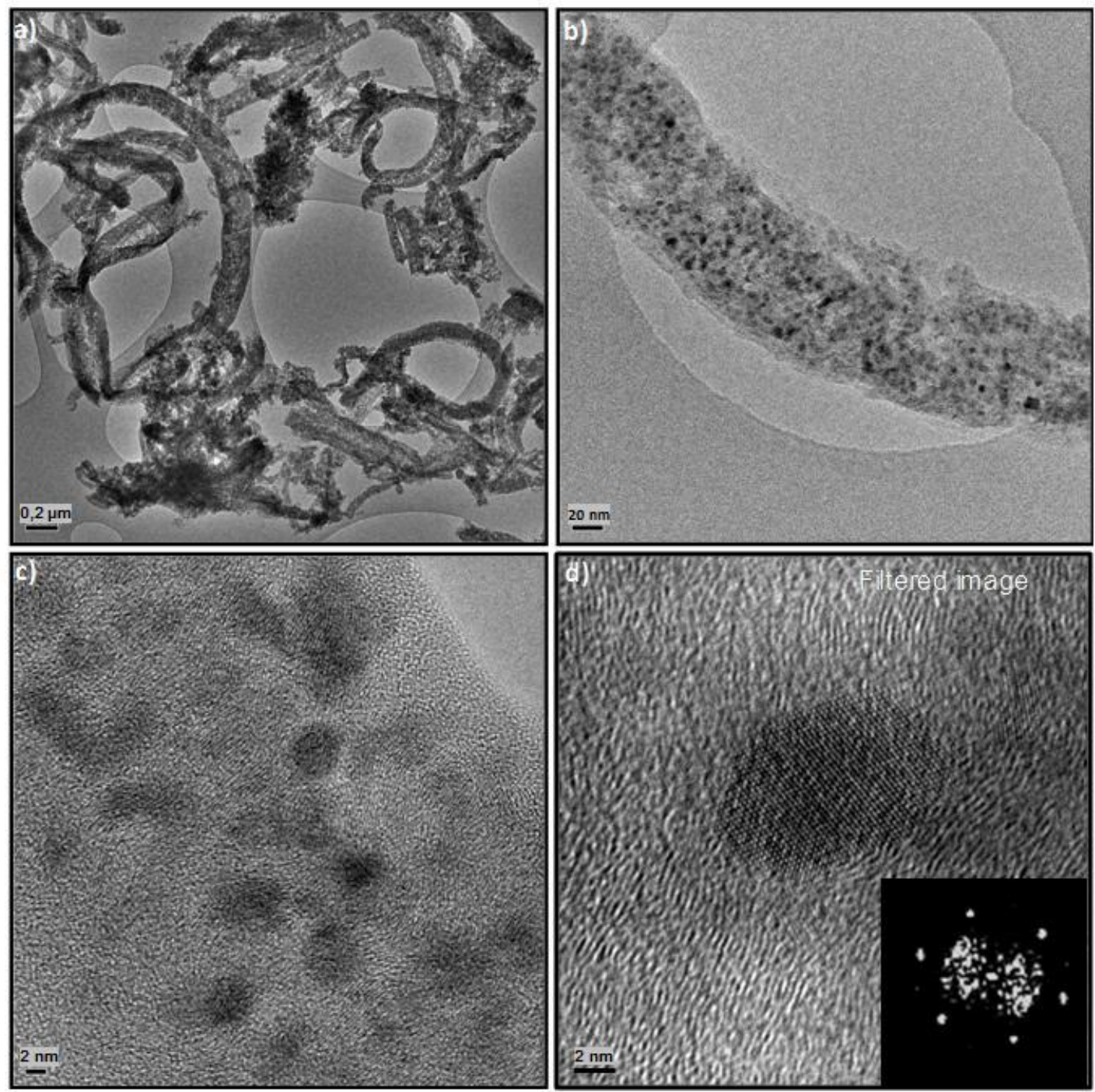

Figure 10 TEM images of the Co-containing CNF/C material (sample C) prepared by the incipient wetness impregnation route on the air plasma treated composite (power=34.5 W, $70 \mathrm{~min}$ ) and further reduced under $\mathrm{H}_{2}$ at $420^{\circ} \mathrm{C}(2.1 \mathrm{wt} \% \mathrm{Co})$

The microscopy images showed that, even for a larger amount of supported cobalt, the particles were still well dispersed along the carbon nanofibers. From the TEM images and 2D Fourier transform diffractograms the particle sizes were comprised between 3 and $5 \mathrm{~nm}$ and constituted of metallic Co with cubic symmetry ( figure $10 \mathrm{~d}$ inset: $\mathrm{d}_{111}=0.20 \mathrm{~nm} ; \mathrm{d}_{200}=0.17$ $\mathrm{nm})$. Again, a $\mathrm{CoO}$ layer was observed on passivated Co particles. A few larger particles were also observed at the surface of the CNF with sizes varying between 10 to $14 \mathrm{~nm}$. 


\section{Conclusions}

The non thermal plasma surface derivatization of novel two-dimensional CNF/C composites made of a carbon preform covered with different percentages of carbon nanofibers led to the formation on the $\mathrm{CNF}$ surface of $\mathrm{C}=\mathrm{O}, \mathrm{C}-\mathrm{O}$ and $\mathrm{O}-\mathrm{C}=\mathrm{O}$ functional groups. Such oxygenbased functionalities are able to develop strong interactions with a cobalt salt precursor leading after reduction to a homogeneous distribution of well-dispersed metallic nanoparticles, as evidenced by the formation of cobalt nanoparticles whose sizes are comprised between 3 and $5 \mathrm{~nm}$ for a cobalt content as high as $2.1 \mathrm{wt} \%$. The non-thermal plasma treatment appears to affect only the CNF and not the carbon fibers constituting their support.

Without non-thermal plasma treatment, neither carbon fibers of the support (carbon preform) nor the CNFs can develop any interaction with the cobalt precursor salt leading, then, to a very low amount of supported cobalt. According to these results, it is expected that such mild CNF air plasma treatment method could be generalized for the control of any supported metallic or oxidic nanoparticles.

\section{Acknowledgements}

The authors are grateful to the "FUI" program (French cross-ministerial fund) and to the AESE Centre - Régions Aquitaine et Midi-Pyrénées under the NAno COmposite MAterials (NACOMAT) consortium for their financial support. J. Souquet-Grumey gratefully acknowledges DGE and Snecma Propulsion Solide Company (SAFRAN Group) for his PhD grant. The authors gratefully thank S. Pronier (IC2MP/Poitiers) for his valuable technical help in the TEM imaging and 2D Fourier transform diffractograms analyses. 


\section{References}

1. Toebes ML, Van Heeswijk JMP, Bitter JH, Van Dillen AJ, De Jong KP (2004) The influence of oxidation on the texture and the number of oxygen containing surface groups of carbon nanofibers. Carbon 42(2): 307-315

2. Zhang G, Sun S, Yang D, Dodelet JP, Sacher E (2008) The surface analytical characterization of carbon fibers functionalized by $\mathrm{H}_{2} \mathrm{SO}_{4} / \mathrm{HNO}_{3}$ treatment. Carbon 46(2): 196-205

3. Ros TG, Van Dillen AG, Geus JW, Koningsberger DC (2002) Surface oxidation of carbon nanofibres. Chem Eur J 8(5): 1151-1162.

4. Xia W, Jin C, jundu S, Muhler M. A (2009) Highly efficient gas-phase route for the oxygen functionalization of carbon nanotubes based on nitric acid vapor. Carbon 47(3): 919-922

5. Xing Y, Li L, Chusuei CC, Hull RV (2005) Sonochemical oxidation of multiwalled carbon nanotubes. Langmuir 21(9): 4185-4190

6. Rasheed A, Howe JY, Dadmun MD, Britt PF (2007) The efficiency of the oxidation of carbon nanofibers with various oxidizing agents. Carbon 45(5): 1072-1080

7. Bandosz T.J. (2009) pp 45-92, In: Carbon Materials for Catalysis, P. Serp and J.L. Figueiredo Eds., John Wiley \& Sons, Inc : New York

8. Chen C, Liang B, Lu D, Ogino A, Wang X, Nagatsu M. (2009) Oxygen functionalization of multiwall carbon nanotubes by microwave-excited surface-wave plasma treatment. $\mathrm{J}$ Phys Chem C 113(18): 7659-7665.

9. Felten A, Bittencourt C, Pireaux JJ, Van Lier G, Charlier JC (2005) Radio-frequency plasma functionalization of carbon nanotubes surface $\mathrm{O}_{2}, \mathrm{NH}_{3}$, and $\mathrm{CF}_{4}$ treatments. $\mathrm{J}$ Appl Phys 98: 074308 
10. Okpalugo TIT, Papakonstantinou P, Murphy H, Mclaughlin J, Brown NMD (2005) Oxidative functionalization of carbon nanotubes in atmospheric pressure filamentary dielectric barrier discharge (APDBD). Carbon 43(14): 2951-2959.

11. Naseh MV, Khodadadi AA, Mortazavi Y, Pourfayaz F, Alizadeh O, Maghrebi M (2010) Fast and clean functionalization of carbon nanotubes by dielectric barrier discharge plasma in air compared to acid treatment. Carbon 48(5): 1369-1379

12. Lee S, Peng JW, Liu CH (2009) Probing plasma-induced defect formation and oxidation in carbon nanotubes by Raman dispersion spectroscopy. Carbon 47(15): 3488-3497

13. Xu L, Fang Z, Song P, Peng M (2010) Surface-initiated graft polymerization on multiwalled carbon nanotubes pretreated by corona discharge at atmospheric pressure. Nanoscale 2(3): 389-393

14. Wen-Hui W, Bi-Chun H, Li-Shan W, Dai-Qi Y (2011) Oxidative treatment of multi-wall carbon nanotubes with oxygen dielectric barrier discharge plasma. Surface and Coatings Technology 205(21-22): 4896-4901

15. Yu H, Cheng D, Williams TS, Severino J, De Rosa IM, Carlson L, Hicks RF (2013) Rapid oxidative activation of carbon nanotube yarn and sheet by a radio frequency, atmospheric pressure, helium and oxygen plasma. Carbon 57: 11-21

16. Kolacyak D., Ihde J. Lommatzsch U. (2011) Carbon nanotube functionalization by atmospheric pressure plasma and post-plasma reactions. Surface \& Coatings Technology 205: S605-S608

17. Zaldivar R.J., Nokes J.P., Adams P.M., Hammoud K., Kim H.I. (2012) Surface functionalization without lattice degradation of highly crystalline nanoscaled carbon materials using a carbon monoxide atmospheric plasma treatment. Carbon 50: 2966-2975 
18. Santos AL, Botelho EC, Kostov KG, Nascente PAP, da Silva LLG (2013) Atmospheric Plasma Treatment of Carbon Fibers for Enhancement of Their Adhesion Properties. Plasma Science, IEEE Transactions on 41(2): 319-324

19. Rhee KY, Park SJ, Hui D, Qiu Y (2012) Effect of oxygen plasma-treated carbon fibers on the tribological behavior of oil-absorbed carbon/epoxy woven composites. Composites Part B: Engineering 43(5): 2395-2399

20. Asedegbega-Nieto E, Guerrero-Ruiz A, Rodriguez-Ramos I (2006) Direct carbon patterning on a conducting substrate in an organic liquid. Carbon 2006 44(4): 799-823

21. Toebes ML, Zhang Y, Hájek J, Nijhuis TA, Bitter JH, Van Dillen AJ, Dmitry Yu. Murzin DY, de Jong KP (2004) Support effects in the hydrogenation of cinnamaldehyde over carbon nanofiber-supported platinum catalysts: characterization and catalysis. J catal 226(1): $215-225$

22. Li Z, Liang C, Feng Z, Ying P, Wang D, Li C (2004) Ammonia synthesis on graphiticnanofilament supported Ru catalysts. J Mol Cat A 211(1): 103-109.

23. Morales-Acosta D, Ledesma-Garcia J, Godinez LA, Rodríguez HG, Álvarez-Contreras L, Arriaga LG (2010) Development of Pd and Pd-Co catalysts supported on multi-walled carbon nanotubes for formic acid oxidation. J Power sources 195(2): 461-465.

24. den Breejen JP, Radstake PB, Bezemer GL, Bitter JH, Froseth V, Holmen A, de Jong KP (2009) On the Origin of the Cobalt Particle Size Effects in Fischer-Tropsch Catalysis. J Am Chem Soc 131(20): 7197-7203.

25. Felten A., Ghijsen J., Pireaux J.-J., Drube W., Johnson R.L., Liang D, Hecq M, Van Tendeloo G, Bittencourt C (2009) Electronic structure of Pd nanoparticles on carbon nanotubes. Micron 40(1): 74-79 
26. Leghrib R, Pavelko R, Felten A, Vasiliev A, Cané C, Gràcia I, Pireaux JJ, Llobet E (2010) Gas sensors based on multiwall carbon nanotubes decorated with tinoxide nanoclusters. Sensors and Actuators B 145 (1): 411-416

27. Larciprete R, Gardonio S, Petaccia L, Lizzit S (2009) Atomic oxygen functionalization of double walled C nanotubes. Carbon 47: 2579-2589

28. Li X (2008) Functionalization of carbon nanofibers with diamine and polyimide oligmer. Carbon 46(8): 1115-1125

29. Harris PJF (2009) Carbon nanotube science: synthesis, properties and applications. Cambrigde university Press.

30. Bezemer LG, Bitter JH, Kuipers HPEC, Oosterbeek H, Holewijn JE, Xu X, Kapteijn F, Jos van Dillen A, de Jong KP (2006) Cobalt Particle Size Effects in the Fischer-Tropsch Reaction Studied with Carbon Nanofiber Supported Catalysts. J Am Chem Soc 128(12): 3956-3964 